\title{
New Analytical HPLC Method Development and Validation for the Simultaneous Quantification of Paritaprevir Ombitasvir and Ritonavirin Spiked Human Plasma.
}

\author{
R.S.CH PHANI ${ }^{1}$, K.R.S. PRASAD ${ }^{1}$ and USENI REDDY MALLU ${ }^{2 *}$ \\ 1Department of Chemistry, K.L. University, Vaddeswaram-522502, Andhra Pradesh, India. \\ ${ }^{2}$ R.V.Labs, Guntur-522007, Andhra Pradesh, India. \\ ${ }^{*}$ Corresponding author E-mail: phani.r.s.ch@gmail.com \\ http://dx.doi.org/10.13005/ojc/330528
}

(Received: June 21, 2017; Accepted: July 05, 2017)

\begin{abstract}
A rapid HPLC bio-analytical method has been developed and validated for the simultaneous quantification of Ombitasvir (OMBTSR), Ritonavir (RTNVR), Paritaprevir (PTVR) in human plasma. OMBTSR and PTVR are used to control Hepatitis-C infection. RTNVR is used in the treatment of HIV/AIDS. The method was developed with Column (Intersil ODSC 18, $250 \mathrm{~mm} \times 4.6 \mathrm{~mm} \times 5 \mu$ ) at $230 \mathrm{~nm}$ wave length and at flow rate of $1.0 \mathrm{~mL} / \mathrm{min}$. The mobile phase consisted of $20 \%$ Acetonitrile, $20 \%$ Methanol, $60 \% 1 \mathrm{mM} \mathrm{NH}_{4} \mathrm{H}_{2} \mathrm{PO}_{4} \operatorname{Buffer}\left(P^{\mathrm{H}} 6.5 \mathrm{v} / \mathrm{v}\right)$. The retention times of RTNVR, OMBTSR, PTVR are $5.7 \mathrm{~min} .7 .8 \mathrm{~min}$. and $12.8 \mathrm{~min}$. respectively. The method was developed and validated in terms of linearity, interday precision, intraday precision, accuracy, LOQ, LOD and stability study. The proposed method is useful in pharmacokinetic studies using HPLC or LC-MS.
\end{abstract}

Key words: Ombitasvir, Ritonavir, Paritaprevir, HPLC Method, Bio analytical method.

\section{INTRODUCTION}

Ritonavir (RTNVR) is an antiretroviral drug used along with other medications to treat HIV/AIDS and hepatitis C. ${ }^{1-3}$. Ombitasvir (OMBTSR) is an antiviral drug for the treatment of hepatitis $C$ virus. Mostly it is used in the combinations with in combination with Paritaprevir, Ritonavir and Dasabuvir $^{4}$. Paritaprevir (PTVR) is best drug in the treatment of hepatitis $C$. The usual side effects of this combination are Diarrhea, Vomiting, loss of appetite and numbness of the hands and feet. The serious side effects are liver problems, pancreatitis, allergic reactions, and Arrhythmias ${ }^{5}$. From last few decades, Pharmacokinetics playing major important role in drug development. At the time of identification of drug's biological properties, metabolic feature of the drug and understanding of pharmacokinetic the bioanalytical methods playing key role. The bioanalytical method used to determine the drug and its metabolites in serum, plasma, urine $e^{6-12}$. 


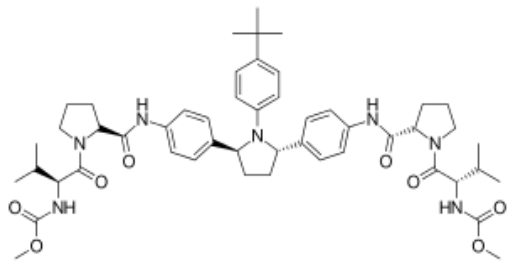

Fig. 1. Structure of OMBTSR

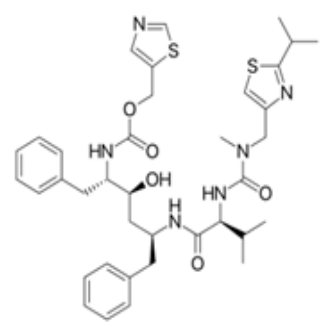

Fig. 2. Structure of RTNVR

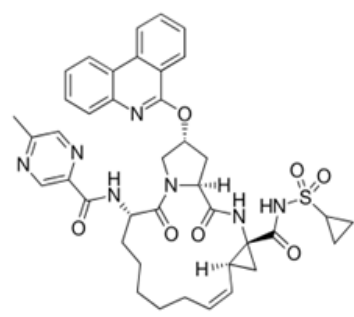

Fig. 3. Structure of PTVR

Literature survey revealed that Nourah Zoman et al ${ }^{12}$ submitted a method for the estimation of RTNVR, OMBTSR, PTVR in pharmaceutical formulations. Other methods are reported for analysis of individual and combination of two drugs. From the literature survey there is no bio analytical method reported. Andrew J Ocque et $a l^{13}$ developed a method to determination of Paritaprevir and Ritonavir in rat liver tissue samples. In this method accuracy range is 6.68 to $10.1 \%$. Jyoti. M. Salunke et al ${ }^{14}$ developed a method to estimate and RTNVR and Lopinavir in combined dosage form with $\mathrm{C} 18$ column $(250 \times 4.6 \mathrm{~mm} \mathrm{id}, 5 \mu \mathrm{m})$ at $1.5 \mathrm{ml} / \mathrm{min}$. flow rate. Methanol, Acetonitrile and Potassium Dihydrogen Phosphate as a mobile phase. Rajasekhar et al ${ }^{15}$ developed a method for LCMS method to determination of Lopinavir and RTNVR in Human Plasma by Protein Precipitation method. The method was developed with mobile phase consisting of $\mathrm{CH}_{3} \mathrm{CN}$ and $5 \mathrm{mM} \mathrm{CH} \mathrm{COONH}_{4}$ buffer. The linearity range of the method is 50.67$10,008.82 \mathrm{ng} / \mathrm{mL}$ for Lopinavir and 5.066-1,000.693 $\mathrm{ng} / \mathrm{ml}$ for Ritonavir. K Vinod Kumar et al ${ }^{16}$ reported a HPLC method developed for the simultaneous quantification of RTNVR and Lopinavir in tablet dosage form and in plasma. The concentration range of Ritonavir and Lopinavir are 5-50 $\mu \mathrm{g} / \mathrm{ml}, 20-200$ $\mu \mathrm{g} / \mathrm{ml}$ respectively. The method was carried out on RP C18 column and methanol: water $(85: 15 \mathrm{v} / \mathrm{v})$ as a mobile phase. $M$ Jagadees waran et $a{ }^{17}$ submitted a method developed a method for quantitative estimation of Lopinavir and RTNVR. The method was reported with reversed-phase C18 Column, mixture of Buffer: Acetonitrile (45:55 v/v) as mobile phase at $p^{H}$ 4.5.The recovery of the method was between $102.1 \%$ and $100.1 \%$ for Lopinavir and Ritonavir respectively. Suneetha. A et a ${ }^{18}$ developed a method for estimation of Lopinavir and RTNVR in combined dosage. The method was developed with Potassium di hydrogen phosphate buffer, $\mathrm{CH}_{3} \mathrm{CN}$ and $\mathrm{CH}_{3} \mathrm{OH}$ in the ratio of $50: 35: 15 \mathrm{v} / \mathrm{v}$ at $\mathrm{pH} 6.0$ linear in the ranges are $400-600 \mu \mathrm{g} / \mathrm{ml}$ for Lopinavir and $100-150 \mu \mathrm{g} / \mathrm{ml}$ for RTNVR.

\section{Objective}

The present study is concerned with the development and validation of RTNVR, OMBTSR and PTVR in spiked human plasma by HPLC.

\section{MATERIALS AND METHODS}

\section{Apparatus}

The new method was developed and validated with Peak LC P7000 HPLC (Isocratic) system rheodyne injector with $20 \mu \mathrm{L}$ and UV/Vis detector UV7000 and PEAK Chromatographic version 1.06. The Ombitasvir, Ritonavir Paritaprevir were scanned with UV-Visible spectrophotometer (Tech comp-UV 2301, make Japan) with Hitachi software. OMBTSR, RTNVR and PTVR were obtained from Manus Aktteva Biopharma LLP (India). HPLC grade solvents Water, Acetonitrile, Methanol and Tri Ethyl Amine (TEA) were procured from Merck, Mumbai. Method was developed at 230 $\mathrm{nm}$ with Intersil ODS C18 column $(250 \mathrm{~mm} \times 4.6$ $m m \times 5 \mu$ ).

\section{Chromatographic conditions}

The HPLC method conditions were optimized by using different columns, different mobile phases and different buffers. The finalized mobile phase is $20 \%$ Acetonitrile, $20 \%$ Methanol, 


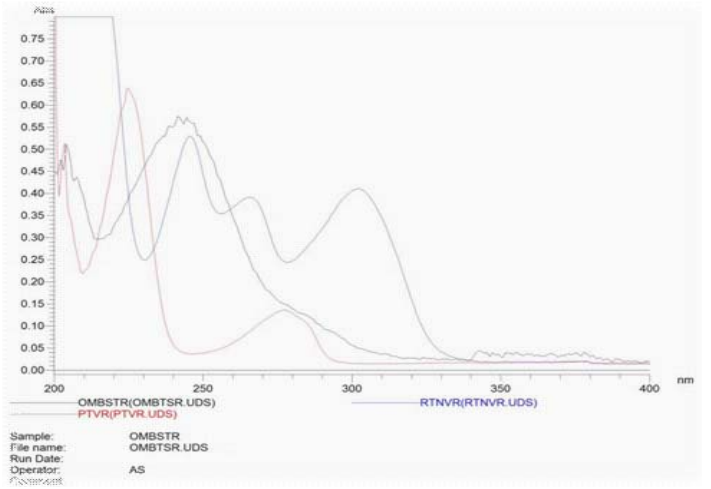

Fig. 4. Overlay of RTNVR, OMBTSR and PTVR

$60 \% 0.001 \mathrm{M} \mathrm{NH}_{4} \mathrm{H}_{2} \mathrm{PO}_{4}$ Buffer v/v. The mobile phase $\mathrm{P}^{\mathrm{H}}$ was adjusted to 6.5 with TEA for perfect separation. Analysis was performed with flow rate $1.0 \mathrm{ml} / \mathrm{min}$. at ambient temperature.

\section{Standard stock solution preparation ${ }^{19}$}

The plasma samples was extracted by liquid-liquid extraction process. The fixed dosages $(10 \mathrm{mg})$ are spiked in to $10 \mathrm{ml}$ plasma and stored in freezer for 24 hours. For processing, the stored spiked samples were taken out from freezer and allowed to thaw at room temperature. An aliquot of $500 \mu \mathrm{L}$ was transferred to prelabeled $10.0 \mathrm{ml}$ polypropylene centrifuge tubes. Extraction solvent, $5.0 \mathrm{ml}$ of ethyl acetate, was then added to extract the drug. The samples were then kept on a vibramax unit and vortexed for 15 minute. Samples were centrifuged at $5000 \mathrm{rpm}$ for $5 \mathrm{~min}$. in a refrigerated centrifuge $\left(4^{\circ} \mathrm{C}\right)$. Supernatant solution, $1 \mathrm{ml}$ was then transferred into pre-labeled polypropylene tubes and was allowed to evaporate to dryness under $\mathrm{N}_{2}$ at $40^{\circ} \mathrm{C}$. The dried residue dissolved in $200 \mu \mathrm{L}$ of mobile phase and transferred into shell vials containing vial inserts for analysis. Samples, $20 \mu \mathrm{L}$ by volume, were then injected into the column and analyzed by HPLC on the same day to avoid any degradation. The column temperature was maintained at ambient temperature.

\section{Validation}

Linearity Test

The Linearity test was conducted in the range of $25 \%$ to $200 \%$. For RTNVR and PTVR the concentrations ranges are 0.15 to $1.2 \mu \mathrm{g} / \mathrm{ml}$. For OMBTR the linearity range is $0.25 \mu \mathrm{g} / \mathrm{ml}$ to $2.0 \mu \mathrm{g} /$ $\mathrm{ml}$. The results are showed in below Table.1. The target concentration solutions are prepared by

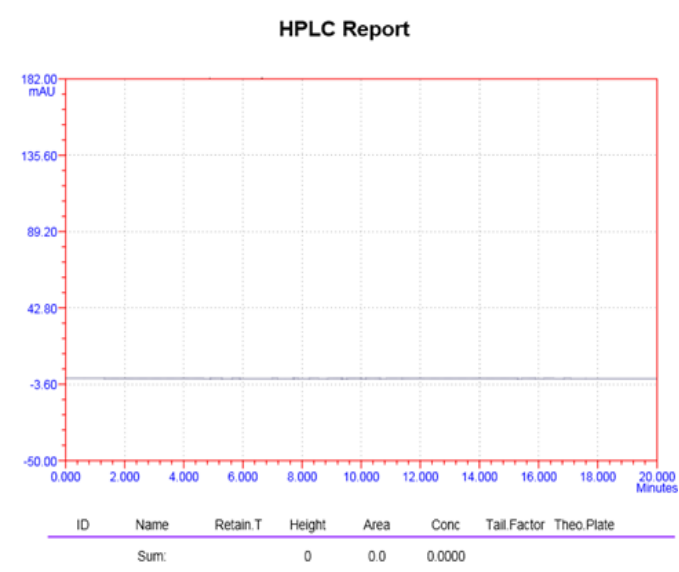

Fig..5 Blank chromatogram

HPLC Report

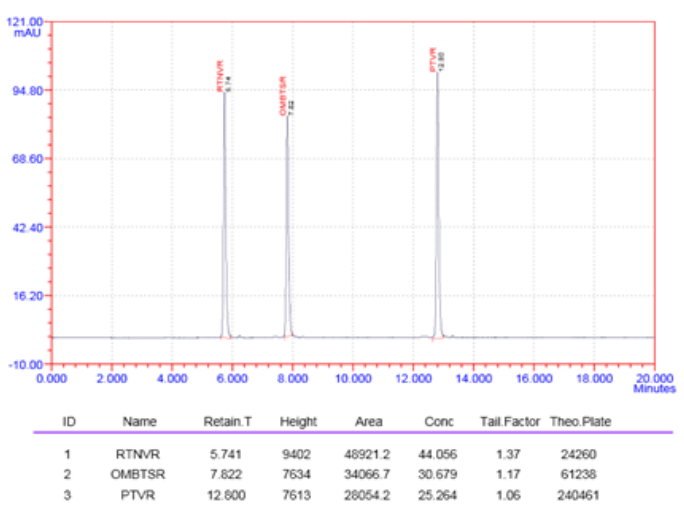

Fig.6. Standard chromatogram of RTNVR.OMBTSR and PTVR

serial dilution from standard stock solution. The linearity graph was plotted with peak area against concentration. The intercept, slope and the correlation coefficient were determined.

\section{Precision}

Intraday precision and Interday precision tests were conducted at standard concentrations of RTNVR, OMBTSR and PTVR i.e $0.6 \mu \mathrm{g} / \mathrm{ml}, 1.0 \mu \mathrm{g} /$ $\mathrm{ml}$ and $0.6 \mu \mathrm{g} / \mathrm{ml}$ respectively. The Precision was expressed as the percentage of RSD(Relative Standard Deviation). The calculated percentage RSD of intraday and inter day precision test of each drug is below 2.0.

\section{Recovery}

The recovery test was conducted at three different concertinos levels 50\%, 100\% and $150 \%$. Recovery of RTNVR, OMBTSR and PTVR was evaluated by comparing of observed peak area with 
Table.1: Linearity results of developed method

\begin{tabular}{lccccccc}
\hline S.No & $\begin{array}{c}\text { Percentage } \\
\text { of } \\
\text { Concentration }\end{array}$ & $\begin{array}{c}\text { Concentration } \\
\text { of } \\
\text { RTNVR }(\boldsymbol{\mu g} / \mathbf{m l})\end{array}$ & $\begin{array}{c}\text { Peak } \\
\text { Area }\end{array}$ & $\begin{array}{c}\text { Concentration } \\
\text { of } \\
\text { OMBTSR }(\boldsymbol{\mu g} / \mathbf{m l})\end{array}$ & $\begin{array}{c}\text { Peak Concentration } \\
\text { area } \\
\text { of }\end{array}$ & $\begin{array}{c}\text { peak } \\
\text { area }\end{array}$ \\
\hline 1 & $25 \%$ & 0.15 & 26025 & 0.25 & 14083 & 0.15 & 10440 \\
2 & $50 \%$ & 0.3 & 33830 & 0.5 & 20759 & 0.3 & 16734 \\
3 & $100 \%$ & 0.6 & 48921 & 1.0 & 34066 & 0.6 & 28054 \\
4 & $150 \%$ & 0.9 & 67191 & 1.50 & 50463 & 0.9 & 42285 \\
5 & $200 \%$ & 1.2 & 79973 & 2.0 & 62630 & 1.2 & 55252 \\
6 & $r^{2}$ & 0.9996 & 0.9990 & 0.9993 & & & \\
7 & Slope & 51833.7 & 28204.73 & 42731.1 & & & \\
8 & Intercept & 18273.97 & 6785.232 & 3632.409 & & & \\
\hline
\end{tabular}

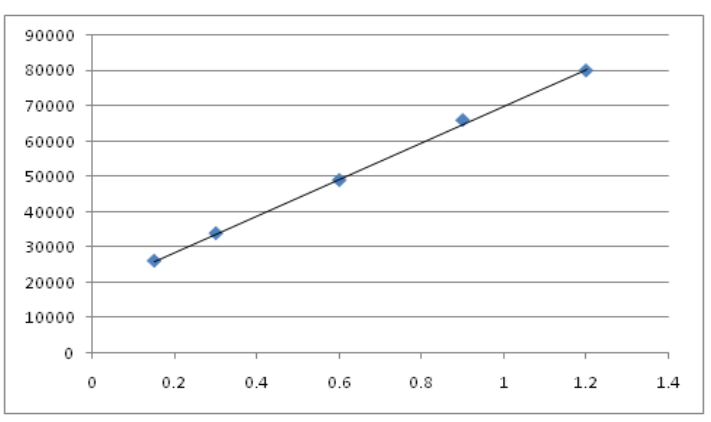

Fig. 7. Linearity graph of RTNVR

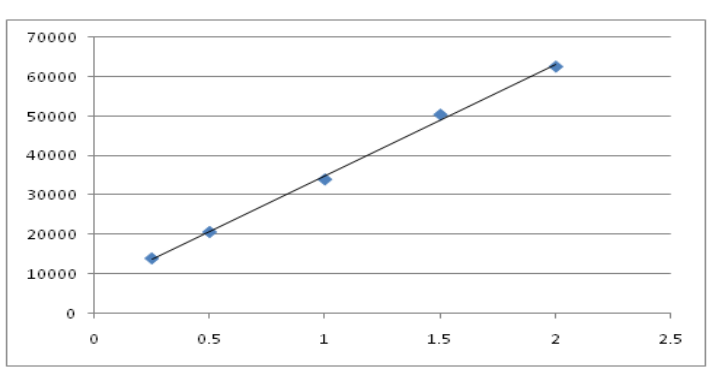

Fig. 8. Linearity graph of OMBTSR

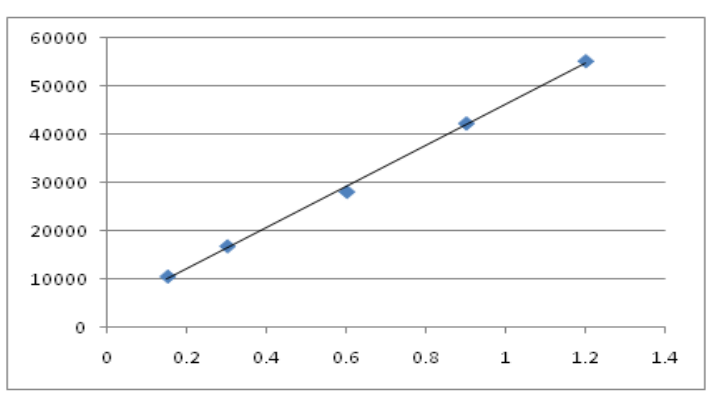

Fig. 9. Linearity graph of PTVR standard peak area. The average recovery of RTNVR is 99.81, OMBTSR is 101.42 and PTVR is 100.38. The results were showed in Table.2.

\section{Sensitivity}

The sensitivity of method was calculated by signal to noise ratio. The plasma sample solution was diluted serially and injected at developed conditions. Similarly, blank plasma samples were also processed and injected. The results were showed in Table.3.

\section{Stability}

The stability experiments were aimed at testing all possible conditions that the samples might experience after collecting and prior the analysis. Short term BT (Bench-Top) stability test was evaluated after $24 \mathrm{~h}$. at room temperature. Autosampler stability test was evaluated on QCs extracts maintained in the auto sampler at $10^{\circ} \mathrm{C}$ for $24 \mathrm{~h}$, by comparing their concentrations with freshextracts. Freeze and Thaw stability test evaluated after three cycles at $-20^{\circ} \mathrm{C}$ to room temperature, by comparison with freshly prepared.Stability of RTNVR, OMBTSR and PTVR solutions was observed at room and temperature and in refrigerated conditions for period of 48 hours. Acceptable stability has been considered as percent difference in concentration lower than $5 \%$. The stability study results were showed in Table.4. 
Table. 2: Recovery results of developed method

\begin{tabular}{|c|c|c|c|c|c|c|c|c|c|}
\hline $\begin{array}{l}\text { Concentration } \\
\text { level }\end{array}$ & RTNVR & $\begin{array}{l}\text { True } \\
\text { area }\end{array}$ & $\begin{array}{c}\% \text { of } \\
\text { recovery }\end{array}$ & OMBTSR & $\begin{array}{l}\text { True } \\
\text { area }\end{array}$ & $\begin{array}{l}\% \text { of } \\
\text { recovery }\end{array}$ & PTVR & $\begin{array}{l}\text { True } \\
\text { area }\end{array}$ & $\begin{array}{c}\% \text { of } \\
\text { recovery }\end{array}$ \\
\hline$\overline{50 \%}$ & 33982 & 33830 & 100.44 & 21011 & 20759 & 101.21 & 16554 & 10734 & 98.32 \\
\hline $100 \%$ & 48689 & 48921 & 99.52 & 34784 & 34066 & 102.1 & 28884 & 28054 & 102.95 \\
\hline $150 \%$ & 66845 & 67191 & 99.48 & 50676 & 50463 & 100.42 & 42237 & 42285 & 99.88 \\
\hline $\begin{array}{l}\text { Average } \\
\text { recovery }\end{array}$ & & & 99.81 & & & 101.42 & & & 100.38 \\
\hline
\end{tabular}

Table. 3: $L O Q$ and LOD results of developed method

\begin{tabular}{llccc}
\hline S. & Test & RTNVR & OMBTSR & PTVR \\
No & & & & \\
\hline 1 & \multirow{2}{*}{ LOQ } & 0.0375 & 0.0625 & 0.375 \\
& & $\mu \mathrm{g} / \mathrm{ml}$ & $\mu \mathrm{g} / \mathrm{ml}$ & $\mu \mathrm{g} / \mathrm{ml}$ \\
2 & LOD & 0.009 & 0.0156 & 0.009 \\
& & $\mu \mathrm{g} / \mathrm{ml}$ & $\mu \mathrm{g} / \mathrm{ml}$ & $\mu \mathrm{g} / \mathrm{ml}$ \\
\hline
\end{tabular}

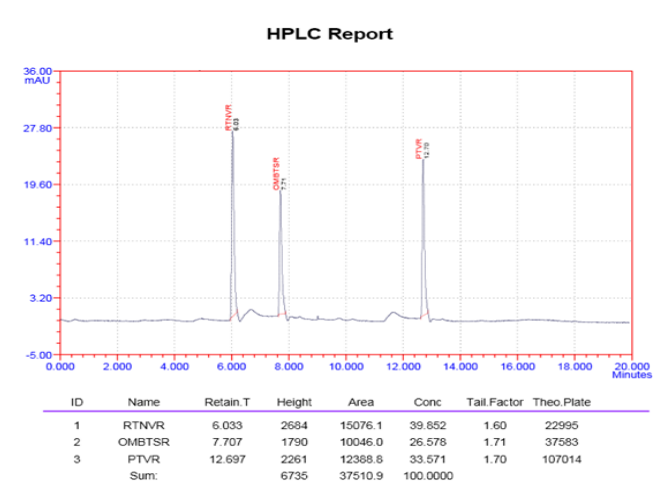

Fig.10. LOQ test chromatogram of RTNVR, OMBTSR and PTVR

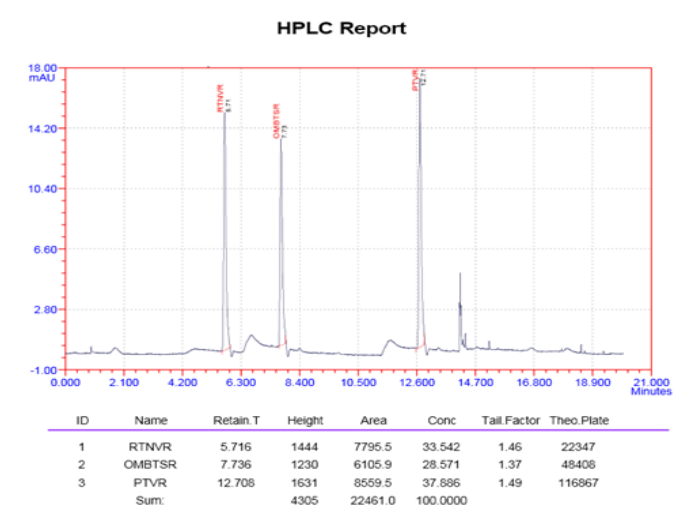

Fig. 11. LOD test chromatogram of RTNVR, OMBTSR and PTVR

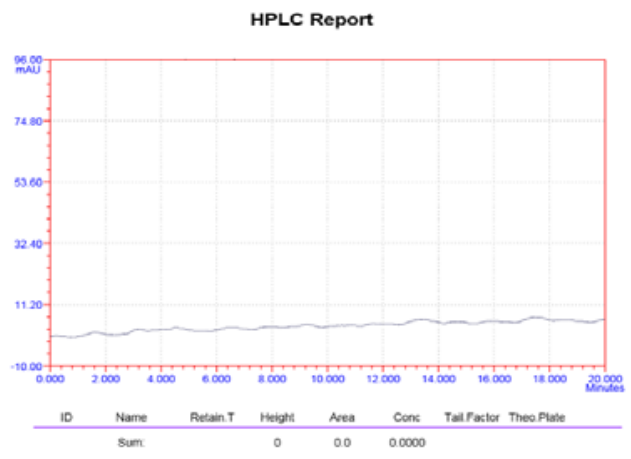

Fig.12. Blank chromatogram of stability test

HPLC Report

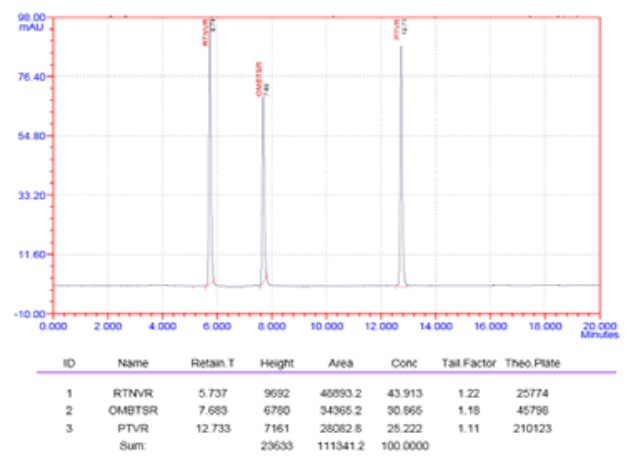

Fig. 13. 1. Stability test chromatogram of RTNVR, OMBTSR and PTVR (Freshly prepared plasma sample)

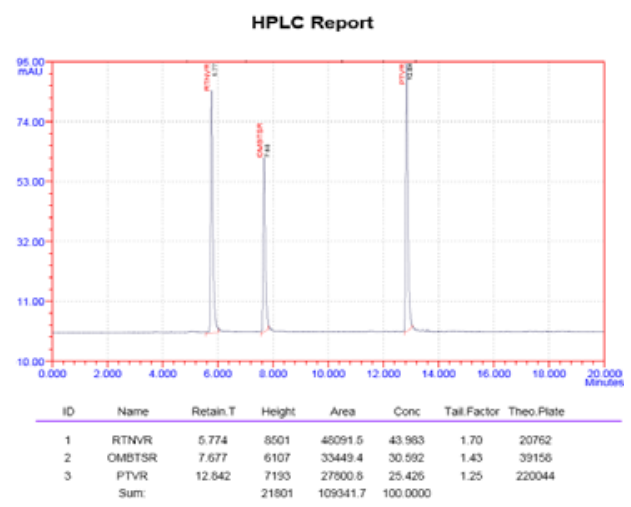

Fig.13. 2. Bench-topstability test chromatogram of RTNVR, OMBTSR and PTVR 


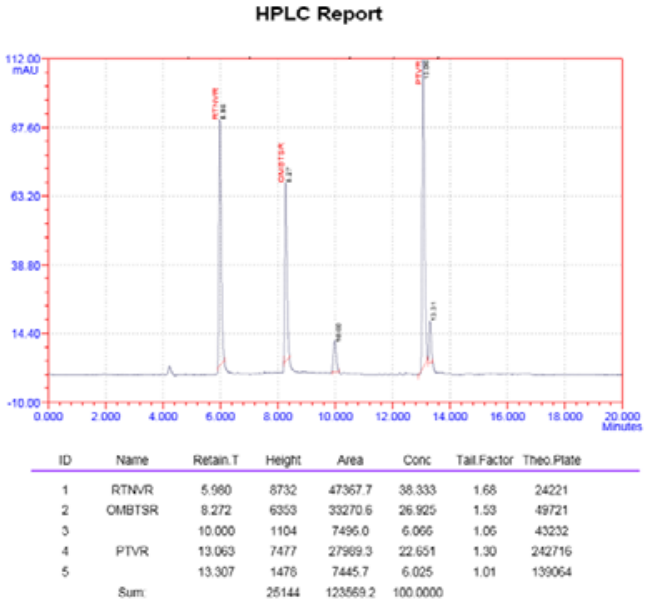

13. 3. Autosamplerstability test chromatogram of RTNVR, OMBTSR and PTVR

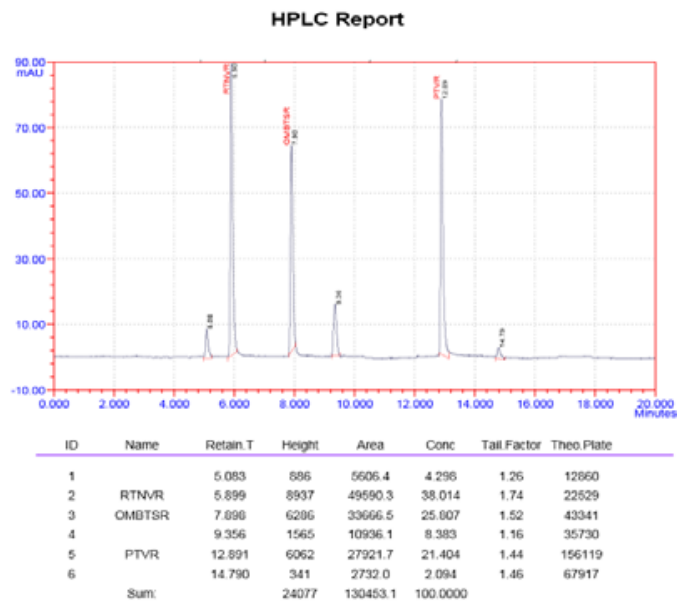

Fig.13. 4. Freeze\& Thawstability test chromatogram of RTNVR, OMBTSR and PTVR

Table. 4: Stability results of developed method

\begin{tabular}{lccccccc}
\hline S.No & $\begin{array}{c}\text { Stability } \\
\text { test }\end{array}$ & RTNVR & $\begin{array}{c}\text { percentage } \\
\text { of change }\end{array}$ & OMBTSR & $\begin{array}{c}\text { Percentage } \\
\text { of change }\end{array}$ & $\begin{array}{c}\text { PTVR } \\
\text { percentage } \\
\text { of change }\end{array}$ \\
\hline 1 & Blank & 00 & 00 & 00 & 00 & 00 & 00 \\
2 & Freshly prepared & 48893 & 0.0 & 34365 & 0.0 & 28082 & 0.0 \\
3 & Bench top & 48091 & 1.65 & 33449 & 2.67 & 27800 & 1.01 \\
4 & Auto sampler & 47367 & 3.13 & 33270 & 3.19 & 27989 & 0.34 \\
5 & Freeze \&Thaw & 49590 & 1.42 & 33666 & 2.04 & 27921 & 0.58 \\
\hline
\end{tabular}

\section{RESULTS AND DISCUSSION}

The developed method was simple, accurate and precise than reported methods. In this method the primarily chromatographic experiments were set to elute selected analytes in biological fluid. The method was validated over the concentration range of $0.15-1.2 \mu \mathrm{g} / \mathrm{ml}$ for RTNVR, PTVR and 0.25$2.0 \mu \mathrm{g} / \mathrm{ml}$ for OMBTSR. The mean percent recovery of RTNVR is $99.81 \%$, OMBTSR is $101.42 \%$ and PTVR is 100.38. The intraday and inter day precision were conducted at standard concentration limits, the Percentage of RSD is below $2 \%$. The LOQ concentrations are $0.0375 \mu \mathrm{g} / \mathrm{ml}$ for RTNVR, PTVR and $0.0625 \mu \mathrm{g} / \mathrm{ml}$ for OMBTSR. Stability (Bench top, Auto sampler, Freeze thaw) of compounds was established in a series of stability studies.

\section{CONCLUSION}

This method is suitable use in clinical studies to determination optimal therapeutic ranges for RTNVR, OMBTSR and PTVR and then for regular analysis and the rapeutically drug monitoring of RTNVR, OMBTSR and PTVR.

\section{ACKNOWLEDGEMENT}

The authors are thankful to M/s. R.V Labs, Guntur for providing necessary laboratory facilities

\section{REFERENCES}

1. The selection and use of essential medicines: Twentieth report of the WHO
Expert Committee 2015 (including 19th WHO Model List of Essential Medicines and 5th 
WHO Model List of Essential Medicines for Children).WHO. 2015, 71.

2. Papaseit Intensive Care Medicine, 2012, 38(7), 1239-1240.

3. British National Formulary (69 ed.), Pharmaceutical Pr., 2015, 426.

4. Jordan J. Feld, N Engl J Med, 2014, 370,1594-1603.

5. Kowdley, New England Journal of Medicine, 2014, 370 (3), 222-232.

6. Ghosh C. J BioequivAvailab, 2011, 3,020-025.

7. Wu XL J BioequivAvailab, 2011, 3, 032-037.

8. Nanjwade BK J BioequivAvailab, 2011, 3, 011-015.

9. Wulandari M, J BioequivAvailab, 2011, 3 , 016-019.

10. Jang IJ, J Bioanal Biomed, 2011, 3, 059-063.
11. Rajender G., Pharm Anal Acta, 2010, 1, 101.

12. Nourah Zoman Al-Zoman., Chem Cent J, 2017, 11, 1.

13. J Ocque., Bioanalysis, 2016, 8(13), 1353-1363.

14. Jyoti M. Salunke Der Pharmacia Lettre, 2013, 5(4), 1-6.

15. Rajasekhar., Chromatographia, 2010, 71(9) 815-824.

16. K Vinod Kumar., IJPRR., 2014, 3 (9)1.

17. Jagadeeswaran M., Pharmaceut Anal Acta., 2012, 3, 160.

18. Suneetha A., International Journal of Pharmacy and Pharmaceutical Sciences, 2011, 3(1), 49-51

19. B. Prasanthi., Journal of Analytical Chemistry, 2015, 70(8),1015-1022 